\title{
Social Media in Micro and Small Third Sector Firms
}

\author{
Simon Wilde \\ School of Business and Tourism, Southern Cross University \\ Locked Mail Bag 4, Coolangatta QLD 4225, Australia \\ E-mail: simon.wilde@scu.edu.au
}

\begin{abstract}
There has been little empirical research and theory development around how small to medium (SME) sized nonprofits are using social media, or how they are attempting to manage the risks associated with social media use, especially in the area of social media policy development. As such, the key aim of this research is to consider how SME non-profits are using social media, in addition to the nature of risk management and policy development within the social media space. Findings from this research may help speak to future strategic directions and policy initiatives for SME non-profit firms as well as broader stakeholder groups.
\end{abstract}

Keywords: social media, SME, nonprofit, third sector, policy.

\section{Introduction}

Non-profit organisations form an essential part of the social, political, and economic landscape of contemporary society. Through the advent of social media, these organisations can gain potential opportunities to increase their community presence, impact, effectiveness, and efficiency ${ }^{1}$. Yet, whilst the development of newer forms of social media communication technologies, such as blogs, instant messaging, and other social media platforms seemingly foreshadowed a change in the communicative potential for organisations globally, many non-profit organisations 'lag behind' in terms of social media adoption. Further to this, non-profits (also commonly referred to as third sector firms) often 'wait to see' how other organisations, particularly other non-profits, incorporate these new communication outlets into their budgets and daily operations before moving forward with their own social media strategy implementation ${ }^{1}$. Only a limited number of studies ${ }^{2,3,4,5}$ have examined aspects of non-profits' social media use from a practitioner perspective. Given the growing emergence of social media, and its widespread impact, including the facilitation of social movements, further research into the area of social media for non-profit business purposes therefore appears both warranted and timely particularly for marketing practitioners, who are at the 'coal face' of social media deployment within the nonprofit sector.

\section{Relevant Literature}

The concept of using social media for business purposes has been top of the agenda for many executives. Since the early 2000s, and the advent of social media networks, business strategists and key marketing personnel have endeavoured to identify ways in which firms can make profitable use of applications such as YouTube, Facebook, Pinterest, and Twitter ${ }^{6}$.

The use of IT to create business value and profitability has been well assessed throughout the literature. In order for a firm to communicate its offering, organisations are required to both build and 
support a community. This community may include customers, suppliers, and other key stakeholders (such as government). As a consequence, it is incumbent of every firm to employ an array of communication tools and mediums. The advent of the Internet subsequently transformed the nature of modern communication platforms $^{7}$. As a growing number of individuals rely upon the Internet as their primary information source (and with internet penetration rates rising, particularly within developing economies), organisations globally have come to recognise the significance of creating innovative and robust Web communication systems in order to connect with core customers. As a consequence, social networking sites such as Twitter, Facebook, and Pinterest have encouraged many key business executives to embed the use of such sites into their broader communication and marketing strategies ${ }^{5}$.

Communication tools, such as social media, afford organisations numerous opportunities. For example, social media sites are able to robustly support the relationship between the management of the firm, and the public, in a responsive and visible way ${ }^{8}$. Further to this, interactive platforms such as social media sites may assist firms in helping them make decisions, to develop stakeholder-focused policies, provide important services, and behave in ways that are both accepted and sought out by important stakeholder groups $^{8,9}$.

Larger firms have been particularly proactive in adopting social media for business purposes. Barnes and Mattson ${ }^{10}$ found that $35 \%$ of Fortune 500 companies had active Twitter accounts in 2009 , which was only three years after the launch of the messaging service. The study further established that $24 \%$ of the Fortune 500 companies actively responded to other users on Twitter and tweeted up to date information. Case studies which investigate the promotional efforts of multi-billion dollar multinationals like Procter and Gamble or General Electric clearly illustrate the underlying value firms such as $P \& G$ and GE gain having entered the social media arena. Both organisations acknowledged the importance of incorporating social media into their marketing communication and promotional efforts ${ }^{11}$. At its very least, for large firms, heavy social media use for marketing purposes appears to be closely aligned with a desire for a high media profile, and its usage (social media) does not appear to be highly impacted by a particular firm's industry or sector ${ }^{12}$.
Not only has social media proven to play an important role for larger corporations, it also becomes increasingly relevant for small and medium-sized enterprises (SMEs) ${ }^{13}$. In the context of this research, SMEs are defined (by the Australian Bureau of Statistics) using the following criteria:

- A small business is an actively trading business with 0-19 employees. As an important subset of small business, micro businesses are small businesses with 0-4 employees.

- A medium business is an actively trading business with 20-199 employees.

In the fast moving SME environment, there is growing evidence that smaller businesses can gain business value from the use of social media for internal and external purposes ${ }^{14}$. Kim, Lee and Lee ${ }^{15}$ analysed the usage of social media platforms in 100 US-based SMEs. Results from this study indicated that whilst most SMEs adopted web 2.0 platforms to some degree, overall SMEs need to increase their efforts to improve their performances, to connect with consumers, and to remain competitive - a key focus for most for-profit firms. In support of the notion of consumer connection, Stockdale, Ahmed and Scheepers ${ }^{16}$ found that the business value of social media, for SMEs, lies primarily in customer engagement. These opportunities, particularly when viewed against 'traditional' weaknesses of SMEs such as limited resources in terms of financial situation, time and marketing skills; the manager's lack of expertise in marketing; and the low visibility and impact of the SME in the market ${ }^{17}$, have the potential to bring a new innovative capacity to the firm, especially when they (social media sites) are used well ${ }^{18}$.

At an academic level, whilst social media has emerged as a new important platform of business communication, there continues to be a lack of research regarding the adoption of these platforms within the non-profit sector ${ }^{2}$. Considering the tremendous impact of social media on public relations, it would therefore also seem reasonable to advocate that social media may also offer opportunities for third sector firms to interact with key public stakeholders, including donors. Limited extant research in this space appears to support this notion. In a study by Curtis et al. ${ }^{19}$, the researchers found that social media tools were becoming beneficial methods of communication for public relations 
practitioners in the non-profit sector. This was particularly evident in organisations with well-defined public relations departments. Such firms were seen to be more likely to adopt social media technologies and use them to achieve their organisational goals. Of course these firms also tend to be larger is scale and scope, as they are able to deploy more resources (eg. marketing support) to sustain innovative market-based practices ${ }^{20}$. Further to this, Curtis et al. ${ }^{19}$ designate that non-profit public relations practitioners were more likely to use social media tools if they find them credible. Other empirical studies support such conclusions.

A 2008 study $^{10}$ which focused on the largest charities in the United States found that a remarkably high $89 \%$ of these large charitable organisations were using some form of social media. A majority $(57 \%)$ of organisations in the sample were using 'blogging' techniques in their social media communications ${ }^{10}$. Given the relatively recent advent of social media platforms at the time of Barnes' and Mattson's ${ }^{10}$ study, these findings provide an early insight as to the growing awareness of the importance of Web 2.0 strategies in meeting business or organisational objectives.

Having investigated a similar sample of the largest 100 non-profit organisations in the United States, Nah and Saxton $^{2}$ found that that organisational strategies, capacities, governance features, and external pressures all play a part in social media adoption and utilisation outcomes. But again an adherence towards strong governance, well-defined organisational strategies, and high capacity (with respect to acquiring managerial talent) is commonly the domain of larger, more established firms ${ }^{21}$.

Subsequently, whilst the above findings help continue to build a generic foundation for the study of social media use within non-profit organisations, they do not actively contribute to the continuing dearth of research which focuses on SME non-profits, and in particular, non-profit firms categorised as very small or 'micro'. In Australia, the number of community or third sector organisations was most recently estimated ${ }^{22}$ at around 600,000 . Some 440,000 of these entities were deemed to be small unincorporated organisations, therefore underpinning the importance of micro enterprises in servicing the needs of the Australian third sector. And much like their small profit-driven counterparts, many marketing challenges are acutely relevant for very small non-profit firms, as organisational size has been identified as an important determinant in a firm's marketing effectiveness ${ }^{23}$. Thus, research which seeks to assess how small and microsized non-profits are using social media has the potential to add strongly to the literature.

In addition to potential benefits associated with nonprofit social media use, there are also possible risks. For example, the use of social media for business purposes has the potential to increase the reputation risk for the firm. Reputation risk is defined as 'the risk that adverse publicity regarding...business practices and associations, whether accurate or not, will cause a loss of confidence in the integrity of the institution, ${ }^{24}$. Eccless, Newquist and Schatz ${ }^{25}$ identify three types of reputation risk factors:

- Risk is increased when the gap between an organisation's reputation and its reality grows;

- Risk is increased by a change in the expectations of consumers;

- When an organisation is internally unable to react to changes in the environment, a highly important source of reputational risk is poor coordination of the decisions made by different business units and functions'.

It can be argued that social media expands the spectrum of reputation risks and boosts risk dynamics ${ }^{26}$. In social media services, users mostly generate unverified information - both true and false - and put forth ideas about organisations that can differ greatly from what organisations share with the public - that is, an organisation's own idea of what it is or what it wants to $\mathrm{be}^{27}$. Social media also fuels new expectations or beliefs about firms, to which organisations should actively respond.

Another example of risk relates to how non-profits often engage in outreach to high-risk populations. This outreach may also include tracking client progress for evaluation purposes ${ }^{28}$. This sort of outreach has the clear potential to increase legal risks. Furthermore, given that non-profit staff members are likely to personally identify with the organisation's mission ${ }^{28}$, they may choose to use their personal social media accounts to engage in nonprofit-related business ${ }^{28}$, again heightening legal risk for the non-profit firm. There has been little empirical research and theory development about how non-profits are attempting to manage such risks associated with social media use. Accordingly, 
investigating social media policy adoption and development within small non-profit firms underpins the second aim of this paper.

\section{Approach and Methodology}

In order to address these research gaps, a sample of 140 senior executives from small to medium sized Australian-based third sector/non-profit organisations were recruited via a permission-based business research panel. This method of respondent sampling has been utilised previously in other non-profit marketing studies (see for example ${ }^{30,31}$ ). Respondents included in the sample indicated a robust familiarity with the marketing activities of their current non-profit organisation. Information such as (but not limited to) the nature of the organisation's marketing activities, size of the firm (in respect to both paid employees and volunteer staff), core industry/sector focus (for example, the environment, culture, health, religious activities etc.), and the overall mission of the organisation were obtained during data collection. Further to this, information pertaining to both social media usage (for non-profit business purposes), and the existence of social media policies and guidelines within the firm was obtained.

A web-based quantitative instrument was employed as part of this research. There are a number of benefits attached to online surveys, both to the researcher and the participant. Cost and time are immediate assets as the distribution of the survey is effected via the Internet, with minimal data costs and drastically reduced distribution and data collection time frames ${ }^{32}$. In contrast to paper-based surveys with delivery irregularities intrinsic to postal mail ${ }^{33}$, online questionnaires enable instant and efficient delivery mode by initiating an invitation bulk email to the potential respondents, exceeding local geographic boundaries expeditiously and efficiently ${ }^{31}$. A major time-saving advantage is that the results from the online survey can be tabulated promptly for entry into a statistics application for analysis ${ }^{34}$.

A number of screening questions were utilised within the survey instrument to ensure the appropriateness of the sample. Firstly, respondents were asked 'Do you currently work for a non-profit firm?' Those that responded in the positive were permitted to continue. Furthermore, the respondents' knowledge of the firm's marketing activities was considered. Only those respondents that indicated to having either (what they perceived as) a limited understanding of the firm's marketing activities, or were fully aware of marketingrelated activities were able to continue with the survey.

\section{Analysis and Findings}

Respondents from a broad array of non-profit sectors (as defined by the International Classification of NonProfit Organisations, which are replicated in the Australian and New Zealand Standardised Industrial Classification) were represented in the data. Healthrelated services $(\mathrm{n}=34)$, social service-based nonprofits $(\mathrm{n}=27)$, and education and research services $(n=17)$ accounted for $56 \%$ of the respondents' current third sector employers. Furthermore, 31\% of respondents noted that their current non-profit employer had a faith-based mission $(n=41) .47 \%$ of firms had less than four (4) paid employees, indicating that their nonprofit meets the Australian industry definition of a 'micro-enterprise'. $19 \%$ of respondents indicated their current employer maintained a paid workforce of between 5 and 6 employees, with 33\% $(\mathrm{n}=47)$ of respondent firms retaining 7-8 paid employees. Sampled firms had a mean of 3-4 volunteers assisting with operational duties within the organisation, again leading to the 'micro-enterprise' nature of many of the non-profits represented in the data.

Of the respondents, $60 \%(\mathrm{n}=86)$ indicated that their current non-profit organisation uses social media for business purposes. Whilst the remaining 54 respondents established that their current non-profit employer does not presently use social media for business-related activities, $39 \%$ of these respondents $(\mathrm{n}=21)$ indicated their firm's willingness to engage social media for business purposes within the next 12 months subsequent to the data collection period.

Respondents were also asked to indicate which social media tools their firm utilised. Perhaps unsurprisingly, Facebook, Twitter and LinkedIn ranked as the three most utilised social media platforms within the majority of SME non-profit firms. Other platforms such as Google+, wikis and photo sharing applications (such as Instagram as an example) were also utilised, but not to the same extent as the leading platforms noted. $59 \%$ of those respondents who indicated the use of social media by their current firm for business purposes, noted that this form of media was used (most frequently) for branding and marketing. Networking 
(56\% of respondents), relationship building (56\%) and public relations $(51 \%)$ also ranked highly in terms of engagement usage frequency (i.e. reason for engaging social media for business purposes). Monetary aspects such as reaching new donors (33\%), fundraising (27\%), and sales $(10 \%)$ ranked amongst the least utilised engagement/usage tactics. Two thirds of respondents (63\%) noted that their non-profit spent, on average, between $0-5$ hours per week on social media-related tasks. $17 \%$ of respondent firms spent between 6-10 hours per week, with 5 respondents noting that their current non-profit spent in excess of $30+$ hours per week dealing with social media-related functions. Almost all (90\%) respondents to the survey indicated that their non-profit firm would likely look to grow the use of social media tools and platforms in the 12 months subsequent to the data collection period.

The final section of the survey instrument dealt with social media policy. Close to half $(46 \%)$ of those respondents who confirmed previously that their current non-profit used social media for business purposes indicated the existence of a social media policy within their firm. Almost half of those policies, in the eyes of the respondent, restricted employee (personal) use of social media during work hours. Restrictions noted by respondents included (but are not limited to):

- No personal use of social media in the workplace, such as Facebook. In some instances, restrictions went further to limit the use of other communication platforms such as Skype as one example.

- Where personal usage of social media was permitted within the workplace, specific time periods or work situations were noted in some policies i.e. staff can access during their lunch break; no more than 20 minutes per day (i.e. specific time allocation); employee 'downtime' - where individuals are waiting on repairs to equipment etc.

- A number of respondents noted that their firm's social media policy called for 'self-control' amongst employees when using social media (for personal reasons) at work.

- Perhaps at the other extreme of the 'self-control' spectrum, a number of respondents reported the installation of internet firewalls and other content control applications within their workplace to restrict social media usage (except for staff involved in the marketing function of the firm).
Given the restrictions noted above, perhaps it is not unexpected that 'guidelines for employee's professional social media use' and 'guidelines for employees personal social media use' ranked most highly in terms of social media policy components. 'Disclosure that social media use may be monitored' and 'guidelines for disclosing contracts, sponsorships, etc' also rated strongly. Generally employees from the non-profit firms were informed of their specific social media policy via some form of internal communiqué (38\%), staff handbook (30\%) or staff meeting (24\%). A not insignificant $15 \%$ of respondents remarked that disciplinary action had been taken against employees (inc. volunteers) at their non-profit organisation relating to social media usage. No other details as to the nature of the various disciplinary incidents were garnered by the researcher.

\section{Highlights of main research findings}

As seen in many for-profit organisations, extant literature contends that non-profits use social media for general marketing and other related functions. The current research validates this notion. In this context, the first finding from this research was the identification of a series of social media engagement strategies, highlighted by senior executives from small and micro sized Australian-based non-profit organisations. The advancement by SME stakeholders of a broad array of engagement and outreach tactics such as branding and marketing, networking, relationship building, and public relations are seen both to support and build upon aspects of social media usage acknowledged by other nonprofit researchers.

\subsection{Key Implications for Practitioners}

The relatively constrained usage of social media platforms for fundraising efforts was also noted in the findings. The rapid diffusion of social media-type services such as Twitter and Facebook is ushering in a new era of possibilities for organisations to communicate with and engage their core stakeholders and the general public ${ }^{35}$. Yet prior studies ${ }^{36,37}$ clearly appreciated that non-profit organisations have struggled in their use of electronic communication tools (such as websites) as strategic, interactive stakeholder engagement tools ${ }^{28}$. The ability to fundraise via social media may well prove to be a critical business function 
worth pursuing by smaller non-profits into the future. Wider research efforts into the area of non-profit marketing within SMEs in Australia ${ }^{38}$ only adds to this conclusion, given that fundraising was gleaned to be the most critical marketing challenge for SME respondents:

'Fundraising is critical as it is the main source of income'.

Key non-profit SME executives further endorsed the existence and relevance of social media policies within their non-profit firm. Up until this point, there has been little empirical research and theory development about how non-profits are attempting to manage the risks associated with social media use ${ }^{28}$. Research pertaining to smaller, micro non-profit firms appears even more scant. The exploratory results presented in this paper therefore provide evidence as to the types of capabilities, resources and policies found within a sample of Australian-based SME non-profits. As a result, this paper attempts to bring the nature of both social media usage and social media policy development within smaller, micro non-profits into sharper focus.

\subsection{Limitations of the Research}

Although the findings from this research indicate that small and micro non-profits are actively using social media as part of business operations, the exploratory nature of this undertaking should be recognised, with only 140 non-profits examined. The sample also consisted exclusively of third sector firms in Australia. Non-profit firms may use social networking sites differently in other countries. A second limitation of this research also relates to sampling. Although the decision to use a permission-based business research panel to contact potential respondents was done so in an effort to ensure that a reasonable number of respondents could be found, a clear limitation here is that other small to micro sized firms (not included on the panel) were not able to take part on the study,

\subsection{Future Research Opportunities}

These limitations do not diminish the importance or relevance of the research findings, but do provide insight into future research priorities. For example, longitudinal studies could offer insights into how nonprofit SMEs change their social networking strategies over time, with detailed case studies from the field helping to illuminate capacity building strategies. It would also be very interesting to ascertain more fully the rationale against the adoption of social media by micro non-profit managers. As noted within the findings of this paper, a sizable percentage of the sample established that their current non-profit employer does not presently use social media for business-related activities. Understanding why this is the case would form an interesting qualitative follow-up investigation.

There also appears a need to further examine social media policy in SMEs. More research is required to fully consider the wide range of issues that have the potential to influence social media policy development, particularly in SMEs.

\section{References}

1. R.D. Waters, The use of social media by nonprofit organizations: An examination from the diffusion of innovations perspective, in Handbook of research on social interaction technologies and collaboration software: Concepts and trends. eds. T. Dumova and R. Fiordo (IGI Publishing: Hershey, PA, 2009).

2. S. Nah and G.D. Saxton. Modeling the adoption and use of social media by nonprofit organizations, New Media \& Society 15 (2013) 294-313.

3. D. Bortree and T. Seltzer, Dialogic strategies and outcomes: An analysis of environmental advocacy groups' Facebook profiles, Public Relations Review 35(3) (2009) 317-319.

4. J. Greenberg and M. MacAulay, NPO 2.0? Exploring the web presence of environmental nonprofit organizations in Canada, Global Media Journal-Canadian Edition, 2 (2009) 63-88.

5. R.D. Waters, E. Burnett, A. Lamm and J. Lucas, Engaging stakeholders through social networking: How nonprofit organizations are using Facebook, Public Relations Review 35 (2009) 102-106.

6. A.M. Kaplan and M. Haenlein, Users of the world, unite! The challenges and opportunities of Social Media, Business Horizons 53 (2010) 59-68.

7. S. Panyam, The Adoption of Social Media in Nonprofit Organizations: The Case Study of the United Nations Country Team in Thailand, Uppsala University Master's Thesis (Uppsala University, 2014).

8. Shahjahan 2015

9. J.E. Grunig, Public Relations and Strategic Management: Institutionalizing Organization. Public Relationships in Contemporary Society, Central European Journal of Communication 1 (2011) 13-31.

10. N.G. Barnes and E. Mattson, Still Setting the Pace in Social Media: The First Longitudinal Study of Usage by the Largest US Charities, University of Massachusetts Dartmouth Center for Marketing Research (2008). 
11. W. Mangold and D. Faulds, Social media: The new hybrid element of the promotion mix, Business Horizons 52(4) (2009) 357-365.

12. J. Grainger, Social media and the Fortune 500: How the Fortune 500 uses, perceives and measures social media as a marketing tool, University of North Carolina Master's Thesis (University of North Carolina, 2010).

13. C. Meske and S. Stieglitz, Adoption and Use of Social Media in Small and Medium-Sized Enterprises, eds. F. Harmsen and H. Proper, Practice-Driven Research on Enterprise Transformation (Lecture Notes in Business Information Processing, 2013) 61-75.

14. P. Geho, S. Smith and S. Lewis, S, Is twitter a viable commercial use platform for small businesses? An empirical study targeting two audiences in the small business community, Entrepreneurial Executive 15 (2010) 73-85.

15. H.D. Kim, I. Lee and C.K. Lee, Building Web 2.0 enterprises: A study of small and medium enterprises in the United States, International Small Business Journal, 31(2) (2013) 156-174.

16. R. Stockdale, A. Ahmed and H. Scheepers, Identifying Business Value From The Use Of Social Media: An SME Perspective, in Proc. Pacific Asia Conference on Information Systems, Ho Chi Minh City, Vietnam, 11-15 July (2012).

17. W.A. Nakara. F. Benmoussa and A. Jaouen, Entrepreneurship and social media marketing: evidence from French small business, International Journal of Entrepreneurship and Small Business 16(4) 386-405.

18. T. Wielicki and L. Arendt, A knowledge-driven shift in perception of ICT implementation barriers: Comparative study of US and European SMEs, Journal of Information Science 36(2) (2010) 162-174.

19. L. Curtis, C. Edwards, K. L. Fraser, S. Gudelsky, J. Holmquist, K. Thornton and K.D. Sweetser, Adoption of social media for public relations by nonprofit organizations, Public Relations Review 36 (2010) 90-92.

20. G. Rubera and A.H. Kirca, Firm Innovativeness and Its Performance Outcomes: A Meta-Analytic Review and Theoretical Integration, Journal of Marketing 76(3) (2012) 130-147.

21. D.L. Dicks, Executive Compensation and the Role for Corporate Governance Regulation, Review of Financial Studies 25(6) (2012) 1971-2004.

22. Productivity Commission, Contribution of the Not-forProfit Sector (Australian Government, 2010).

23. R. Bennett, Market Orientation Among Small to Medium Sized UK Charitable Organizations: Implications for Fund-Raising Performance, Journal of Nonprofit and Public Sector Marketing 6(1) (1998) 31-45.
24. C. Eckert and N. Gatzert, Modeling Operational Risk Incorporating Reputation Risk: An Integrated Analysis for Financial Firms, Working Paper (Friedrich Alexander University Erlangen) (2015).

25. R.G. Eccles, S.C. Newquist and R. Schatz, Reputation and its risks, Harvard Business Review 85(2) (2007) 104-14.

26. A. Pekka, Altered images, Communication Director 10 76-79.

27. A. Pekka, Social media, reputation risk and ambient publicity management, Strategy \& Leadership 38(6) 4349.

28. J. Jones, Nonprofit Social Media Policies: Managing Risk, Maximizing Opportunities, in Proc. 10th International Conference of International Society for Third Sector Research, Siena (Italy), July 10-13 (2012).

29. W.W. Powell and R. Steinberg (eds.), The Nonprofit Sector: A Research Handbook, $2^{\text {nd }}$ edn. (Yale University Press, New Haven and London, 2006)

30. S. Dolnicar and K. Lazarevski, Marketing in non-profit organizations: an international perspective, International Marketing Review 26(3) (2009) 275-291.

31. D.Z. Basil, S. Deshpande and M. Runte, The Impact of Cause-related Marketing on Nonprofit Organizations, in Proc. Partnerships, Proof and Practice - International Nonprofit and Social Marketing Conference, University of Wollongong, 15-16 July (2008).

32. C. Medin, S. Roy and T. Ann, World Wide Web versus mail surveys: A comparison and report, in Proc ANZMAC Conference, Sydney, Australia (1999).

33. A. Crowley, E-mail surveys elicit fast response, cut costs, PC Week 30 (1995) 65.

34. M. Bryant, Information Systems Applications: User Acceptance, Trust and Value of Weather Apps on Smartphones, Southern Cross University Honours Thesis (Southern Cross University, 2014).

35. K. Lovejoy and G. Saxton, Information, Community, and Action: How Nonprofit Organizations Use Social Media', in Proc Conference of the International Communication Association, Boston, May 26-30 (2012).

36. M.L. Kent, M. Taylor and W.J. White, The relationship between Web site design and organizational responsiveness to stakeholders, Public Relations Review 29 (2003) 63-77.

37. G.D. Saxton, C. Guo and W. Brown, W, New dimensions of nonprofit responsiveness: The application and promise of Internet-based technologies, Public Performance and Management Review 31 (2007) 144-173.

38. S. Wilde, B. Burgess and R. Laffey, Critical Marketing Challenges for Small to Medium Sized Non-Profit Firms: An Australian Perspective', in Proc Rome Conference of the International Journal of Arts \& Sciences, Rome (Italy), October 22-25 (2013). 